\title{
Evolution de l'état corporel de brebis Mérinos d'Arles en fonction de la ressource fourragère de printemps. Répercussion sur les performances ultérieures
}

\author{
P Lapeyronie, G Molénat, M Vincent
}

INRA ENSA.M, 2 Place Viala 34000 Montpellier, France

En régions méditerranéennes les ressources pastorales de printemps sont aléatoires. Dans les systèmes d'élevage ovins extensifs méditerranéens avec agnelage d'automne, elles conditionnent la reconstitution précoce des réserves corporelles induisant même des effets sur la lactation suivante. Une légumineuse fourragère annuelle, le trèfle souterrain, a été évaluée sur son aptitude à améliorer l'état corporel au printemps de brebis Mérinos d'Arles transhumantes de la Crau. Trois lots de 20 brebis ont été constitués au printemps 1993. De début mars à fin mai, ils pâturaient, l'un une végétation à base de trèfle souterrain ( $T$ ), l'autre la végétation de parcours steppique spontanée (S) et le troisième successivement du trèfle souterrain jusqu'à miavril puis le parcours steppique (M). Les trois lots disposaient de la même quantité de biomasse végétale. Après la fin mai ils étaient regroupés et conduits de manière identique. Des notations périodiques d'état corporel (Russel et al, 1969, J Agric Sci Camb, 72, 451454) ont été effectuées. Leurs agneaux nés à l'automne étaient soumis à des pesées régulières. L'expérimentation a été répétée en 1994 avec les mêmes brebis. Les données ont été analysées à l'aide de modèles d'analyse de la variance (SAS Institute INC).

Sur la note d'état corporel les effets du lot de pâturage sont significatifs en avril, mai, juillet et août $(p<0,001)$ et jusqu'à la mise bas en septembre $(p<0,01)$. L'analyse sur les variations d'état depuis la fin de l'hiver (différence par rapport à la note attribuée en février), indique que l'effet du lot de pâturage reste significatif jusqu'en août $(p<0,05)$. Les variables relatives aux performances des agneaux nés et allaités simples, poids de naissance $(P N)$, poids à 10 et à 30 jours ( $P 10$ $P 30$ ) et gain quotidien entre 10 et 30 jours (GMQ) ont été analysées en considérant l'effet des différences de notes des mères (procédure GLM). Les résultats montrent un effet significatif $(p<0,05)$ de la reprise d'état des mères au printemps sur les performances des agneaux. Une écart de gain de 0,5 point entre février et mai se traduit par $120 \mathrm{~g}$ de différence sur PN, $240 \mathrm{~g}$ sur $P 10$ et $470 \mathrm{~g}$ sur P30 L'écart calculé entre février et juillet n'entraîne plus de différence sur $P N$, en revanche les différences sur $\mathrm{P} 10$ et $\mathrm{P} 30$ sont augmentées, respectivement 280 et $530 \mathrm{~g}$.

Ces résultats confirment l'influence d'une reconstitution précoce des réserves corporelles au printemps sur la production laitière à l'automne suivant. Les végétations spontanées ne permettent qu'une amélioration trop lente de l'état corporel au début du printemps. Avec une ressource fourragère améliorée à base de légumineuses rustiques, la reconstitution des réserves maternelles est plus rapide. Le gain acquis est conservé jusqu'à l'agnelage d'automne et se traduit par une meilleure croissance des agneaux.

\begin{tabular}{lcccccc} 
Lots & \multicolumn{2}{c}{$\mathrm{T}$} & \multicolumn{2}{c}{$\mathrm{S}$} & $\mathrm{M}$ \\
Notes (sur 5): & $\mathrm{m}$ & $\mathrm{s}$ & $\mathrm{m}$ & $\mathrm{s}$ & $\mathrm{m}$ & $\mathrm{s}$ \\
Février & 2,7 & 0,1 & 2,6 & 0,2 & 2,9 & 0,1 \\
Avril & 3,1 & 0,1 & 2,4 & 0,1 & 3,2 & 0,1 \\
Mai & 3,5 & 0,1 & 2,7 & 0,1 & 3,4 & 0,1 \\
Juillet & 3,4 & 0,1 & 2,7 & 0,1 & 3,2 & 0,1 \\
Août & 3,6 & 0,1 & 3,0 & 0,1 & 3,4 & 0,1 \\
Septembre & 3,3 & 0,2 & 2,6 & 0,2 & 3,3 & 0,2 \\
\hline
\end{tabular}

Effet du lot de pâturage
S
0,1
0,1
0,1
0,2 